\title{
Novel properties of Epipremnum aureum for treatment of fluoride-contaminated water
}

\author{
K. P. Singh ${ }^{1}$ (D) A. Shyam Kumar ${ }^{1} \cdot$ M. Paniteja ${ }^{1} \cdot$ Smita Singh $^{2}$
}

(c) Springer Nature Switzerland AG 2019

\begin{abstract}
Groundwater is the primary source of drinking water, and high concentrations of fluoride in it may cause skin diseases, crippling of bones and brain damage. Three plants have been considered, namely money plant, water hyacinth and duckweed for removal of fluoride from water without supplying any nutrients to these plants. It is found that water hyacinth and duckweed died in fluorided and highly alkaline groundwater $(\mathrm{pH} \approx 9)$ within 10 days. However, consistent growth is observed in the money plant (Epipremnum aureum). Preliminary results of this study demonstrate that money plant can remove both fluoride and the total dissolved solids from contaminated water and can survive for more than 2 months without nutrients. Furthermore, water physicochemical analysis shows that money plant can accumulate dissolved heavy metals and anionic contaminants such as chloride and sulfate. Unlike other plants, the money plant can adapt to temperate, tropic and subtropic climatic conditions, and therefore, it may be a potential candidate for the cost-effective, green and sustainable fluoride treatment for fluoride-contaminated water.
\end{abstract}

Keywords Phytoremediation · Fluoride · Epipremnum aureum ·TDS

\section{Introduction}

Fluoride $\left(\mathrm{F}^{-}\right)$contamination is a worldwide problem as it is the very persistent and non-biodegradable pollutant that enters into the water through different natural and anthropogenic sources [1, 2]. Consumption of water with high fluoride concentrations can result in adverse impacts on human health like dental caries, lesions of the thyroid, endocrine glands, brain damage, osteoporosis, bone fluorosis [3]. The permissible limits of fluoride in water are $0.5-1.5 \mathrm{mg} / \mathrm{L}$ as per World Health Organization (WHO) standards [4]. The fluoride-rich sources of rocks and their interactions with water for a prolonged time also enhance the fluoride levels in water $[5,6]$. Numerous low-cost materials have been used for fluoride removal such as brick powder as adsorbent [7], natural soil [8], $\mathrm{MnO}_{2}$-coated tamarind fruit (Tamarindus indica) shell [9], apatite materials in aqueous solution [10] and waste mud [11]. Recent laboratory studies also suggest that hybrid biogeochemical techniques, which combine chemical and biological treatment methods, are very effective in the treatment of fluoride in wastewaters and groundwater [12-14]. There are many districts in Telangana state, India, which are polluted by fluoride, out of which commonly noted district is Nalgonda, and the overall fluoride levels observed were in the range of $0.1-20 \mathrm{mg} / \mathrm{L}$ in different studies $[15,16]$. Phytoremediation is widely known for removing heavy metals from soil and different sludges $[17,18]$. It is defined as the use of plants to remove pollutants from the environment and restore balance [19]. Zhou et al. (2012) have used five submerged plants for fluoride removal from water, and their studies related to $\mathrm{F}^{-}$ions show an adverse effect on the physiological function of plant and their growth [20-22]. A vast variety of plants were tested to find the best fluoride accumulator such as an Eichhornia crassipes, Spirodela polyrhiza, Hydrilla verticillata, Camellia sinensis (L.)

K. P. Singh, kpsingh@ngri.res.in | ${ }^{1}$ CSIR-National Geophysical Research Institute, Hyderabad 500007, India. ${ }^{2}$ Delhi Public School Nacharam, Hyderabad 500007, India.

SN Applied Sciences (2019) 1:741 | https://doi.org/10.1007/s42452-019-0773-0 
O. Kuntze roots of tea plants, Pistia stratiotes. Urtica dioica L. [23-28]. Here, the activity of Epipremnum aureum (money plant) associated with fluoride removal in conjunction with duckweed and water hyacinth has been investigated. Epipremnum aureum belongs to family Archaea and is native to southeastern Asia and New Guinea [29]. It is an ornamental plant mostly seen in every household hanging in pots or plastic bottles. It has antimicrobial properties, and it is a potential accumulator of both dissolved heavy metals and air pollutants [30, 31].

The various properties of the money plant have motivated us to consider this plant in the present study, and therefore, an experimental study was carried out to find the potential of $E$. aureum in the defluoridation process. The use of a money plant in defluoridation has not yet been reported anywhere in the literature.

\section{Experimental protocols}

A laboratory experiment was conducted by using $E$. aureum, with natural fluoride-contaminated water. Three similar glass beakers A, B, and C were filled with $500 \mathrm{ml}$ of field samples in triplicates in which money plant, water hyacinth and duckweed were planted in these beakers, respectively (Fig. 1). Water samples were collected in 1-I polyethylene plastic bottles as per the standard American Public Health Association (APHA) method from Kurmedu village in Nalgonda district, India [32]. In previous studies related to phytoremediation of contaminants, the plants were grown hydroponically by using Hoagland solution [33]. However, an effort has been made to find out the plants, which can survive by utilizing TDS and other minerals present in natural water. To achieve this task, plants

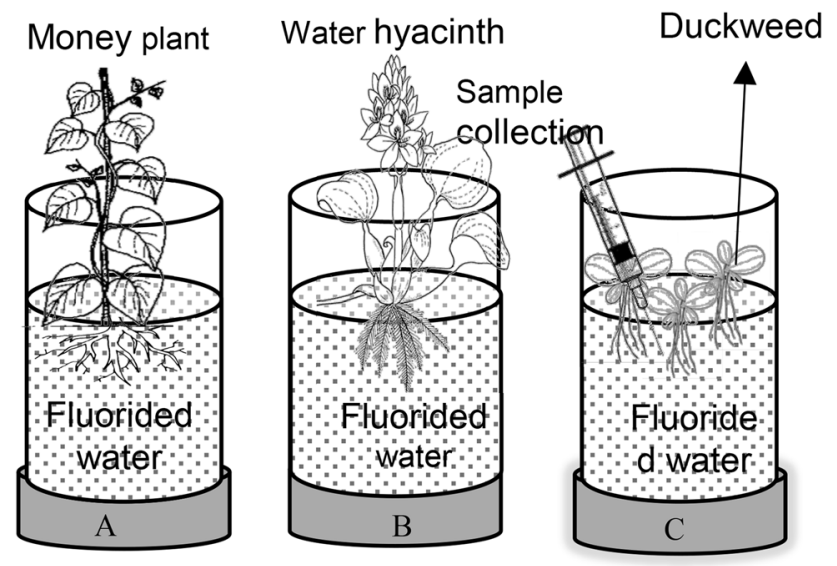

Fig. 1 Experimental setup consisting of three similar beakers A, B and $C$ filled with fluorided groundwater collected from Kurmedu village in Nalgonda district, Telangana (India); money plant, water hyacinth and duckweed are planted in beakers, respectively were grown at room temperature without adding nutrients to the water. The initial concentration of fluoride in samples was measured as $3.44 \mathrm{ppm}$.

\subsection{Measurement of physicochemical parameters}

The core physicochemical parameters like $\mathrm{pH}$, redox potential $(\mathrm{mV})$, TDS $(\mathrm{mg} / \mathrm{L})$, fluoride concentration $(\mathrm{mg} / \mathrm{L})$ and conductivity ( $\sigma$ in $\mathrm{mS} / \mathrm{cm}$ ) were measured every fifth day. Five milliliters of a water sample is collected for the measurement of chemical parameters by using a new syringe (Fig. 1). An electrochemical analyzer (Consort C6030, Topaz Inc., USA) kit was used to measure water physicochemical parameters. These parameters were measured by using respective electrodes connected to the analyzer which were cleaned with deionized (DI) water before and after the measurements to avoid contamination.

\subsection{Measurement of fluoride concentration}

Ion-selective electrode (ISE) is used for the estimation of fluoride concentration in water samples collected from the experiment. ISE is based on the principle that the electrical potential measured by ISE is proportional to the negative logarithm of activity of fluoride [34, 35]. The minimum sample volume of $10 \mathrm{ml}$ is required for the estimation of fluoride concentration by ISE method. Thus, water samples $(10 \mathrm{ml})$ were collected for the estimation of fluoride concentration at regular interval of 5 days. Fluoride $\left(\mathrm{F}^{-}\right)$in the sample was analyzed by adding $10 \mathrm{ml}$ of sample collected and $10 \mathrm{ml}$ of ISA (lonic strength adjuster) into a beaker.

\subsection{Determination of fluoride content in different parts of plant}

After completion of the experiment, different parts of the plant are separated and dried for the estimation of fluoride accumulation in the plant. Fluoride concentration was estimated by adopting the methodology described elsewhere $[36,37]$. Fluoride concentration in leaf, leaf attachments, stems and roots was determined by extracting the ground and sieved samples with $0.1 \mathrm{~N}$ perchloric acid.

\subsection{Trace metal and anionic analysis}

Trace metals were detected in water using inductively coupled plasma-atomic emission spectroscopy (ICP-AES). ICP-AES analysis was performed on a fresh sample at the beginning and the end of the experiment. Concentrations of major anions are measured using ion chromatography (IC) twice during the entire period of the experiment. Samples $(10 \mathrm{ml})$ were collected and filtered through the filter papers of grade HM1 $(11 \mu \mathrm{m})$ for removing suspended 
particles and then stored in $15-\mathrm{ml}$ glass bottles. Sample bottles were sealed with parafilm and stored in $4^{\circ} \mathrm{C}$ temperature in the refrigerator for eliminating the further degradation of the sample. The anionic analysis was carried out by using a sterile syringe or bottle rinsed three times with sample water and then filtered through $0.45 \mu \mathrm{m}$ (or smaller) filters. The collection vials should likewise be rinsed three times with filtrate before being filled brim/ full of the sample filtrate. The minimum volume of sample required for cationic analysis is approximately $5 \mathrm{ml}$.

\subsection{Measurement of evapotranspiration}

After sample collection on every fifth day for measurements of chemical parameters and estimation of fluoride concentration, new marks were labeled on the beakers. Any decrease in water level below the new mark is the measure of loss of water via evapotranspiration. Water loss through evapotranspiration (EVT) is compensated by pouring DI water up to the mark on respective measurement days. The water loss by evaporation only reduces the volume of water and does not cause a reduction in dissolved chemical species. Both evaporated water and DI water contain the negligible concentration of chemical species. Thus, the addition of DI water for compensation for loss of water due to evaporation will not affect the chemical properties of contaminated water.

\subsection{Plant growth and weight measurements}

The wet weight of the plant (WWOP) is estimated every fifth day to get information on the biomass accumulation. Some visual observations are made such as an increase in the length of the plant, growth of leaves and roots. Any growth in plants in alkaline and fluorided water may be an indicator of tolerance of the plant. The growth measurements may provide information about the ability of plant survival in highly alkaline and fluoride-contaminated water without any added nutrients. WWOP is calculated as

$W W O P=W_{T}-W_{b}-W_{W}$

where $W_{T}=$ total weight of the experimental setup up including beaker, plant and water, $W_{\mathrm{b}}=$ weight of the empty beaker, $W_{\mathrm{w}}=$ weight of the water in the beaker (volume of the water multiplied by the density of water).

\section{Results and discussion}

Duckweed and water hyacinth died within 10 days, and therefore, activities of these plants have not been discussed in this section. These plants may require additional nutrients for their survival. The quality analysis of observed data is performed by fitting linear and polynomial functions to various observed and calculated parameters. The quality assurance has been determined by computing $R^{2}$ (coefficient of determination) and standard error $(\mathrm{SE}=$ standard deviation $(s) / \sqrt{n}$, ' $s$ ' is a standard deviation and ' $n$ ' is a number of observations). Standard error is inversely proportional to square root of total number of observations, and therefore, it decreases with increase in number of observations. An excellent fit between fluoride concentration and time $\left(R^{2}=0.9912\right)$ has been found, and the standard error in measurements has been represented by error bars $(\mathrm{SE}=0.376)$. It is observed that fluoride removal has taken place at a constant rate of $0.021 \mathrm{ppm} /$ day from 3.43 to 2.81 ppm (Fig. 2a). Consistent decrease in $\mathrm{F}^{-}$concentration up to day 30 signifies that money plant may be a potential fluoride accumulator. The standard errors in Fig. $2 b-d$ have been represented by errors, and SE varies from 0.5 to 0.3 . Results thus obtained from total fluoride estimation in different parts of the plant indicate that leaf and leaf attachments contain $52 \%$ of total accumulated fluoride, whereas $48 \%$ of total accumulated $\mathrm{F}^{-}$is absorbed by root and stems (Fig. 2b). Anionic analysis of the freshwater sample and the sample collected after the completion of an experiment on day 30 shows a significant decrease in concentrations of $\mathrm{F}^{-}$, chloride $\left(\mathrm{Cl}^{-}\right)$and sulfate $\left(\mathrm{SO}_{4}{ }^{2-}\right)$. However, nitrate $\left(\mathrm{NO}_{3}{ }^{-}\right)$, nitrite $\left(\mathrm{NO}_{2}{ }^{-}\right)$, phosphate $\left(\mathrm{PO}_{4}{ }^{3-}\right)$ and bromide $\left(\mathrm{Br}^{-}\right)$were not present in the water samples (Fig. 2c). Reduction in estimated concentrations of $\mathrm{F}^{-}(44.7 \%), \mathrm{Cl}^{-}(10.89 \%)$ and $\mathrm{SO}_{4}{ }^{2-}(7.49 \%)$ signifies that the money plant could be a potential accumulator of fluoride. The concentrations of dissolved metals in water samples including $\mathrm{Ca}$ (55.4\%), $\mathrm{K}$ (53.5), $\mathrm{Cu}(40.88 \%)$ and $\mathrm{Cr}(37.18 \%)$ have been depleted (Fig. $2 \mathrm{~d}$ ). Significant reduction in the concentrations of $\mathrm{Cu}$ and $\mathrm{Cr}$ suggests that there is a possibility of removal of heavy metals by money plant. However, iron (Fe) has not been found both in a fresh sample and in the sample analyzed after the completion of the experiment. Variations in $\mathrm{pH}$ and $\mathrm{Eh}$ of the water samples were measured at a regular interval of 5 days. It has been observed that $\mathrm{pH}$ has increased from 7.66 to 9.02 and Eh (mV) from -119 to 39.80 (Fig. 3a). Variations in $\mathrm{pH}$ and Eh within 10 days were attributed to the rapid uptake of calcium (Ca) and magnesium (Mg) by the plant, which are conjugate acids of weak bases. Both $\mathrm{Ca}$ and $\mathrm{Mg}$ form weak bases in aquatic systems as $\mathrm{Ca}(\mathrm{OH})_{2}$ and $\mathrm{Mg}(\mathrm{OH})_{2}$. The hydroxides of calcium $\left(\mathrm{Ca}(\mathrm{OH})_{2} \leftrightarrow \mathrm{Ca}^{2+}+2 \mathrm{OH}^{-}\right)$and magnesium $\left(\mathrm{Mg}(\mathrm{OH})_{2} \leftrightarrow\left(\mathrm{Mg}^{2+}+2 \mathrm{OH}^{-}\right)\right.$ionized in aqueous system. Accumulation of $\mathrm{Ca}^{2+}$ and $\mathrm{Mg}^{2+}$ in plant resulted in elevated concentration of hydroxyl ion $\left(\mathrm{OH}^{-}\right)$, which was responsible for increase in $\mathrm{pH}$ of the water. The temperature could not be maintained in the laboratory during the first week, and after that, it was maintained at $25^{\circ} \mathrm{C} \pm 1{ }^{\circ} \mathrm{C}$. 
Fig. 2 a Fluoride concentration in water decreased linearly within 30 days: $\mathbf{b}$ accumulation of fluoride in different parts of the plant, $\mathbf{c}$ maximum decrease in $\mathrm{F}^{-}$(44.7\%) followed $\mathrm{Cl}^{-}(10.8 \%)$ and $\mathrm{SO}_{4}{ }^{2-}$ (7.5\%), d concentrations of dissolved metals including $\mathrm{Ca}(55.4 \%)$, $\mathrm{K}(53.5 \%), \mathrm{Cu}(40.88 \%)$ and $\mathrm{Cr}$ (22\%) were depleted (error bars represent standard error in data)

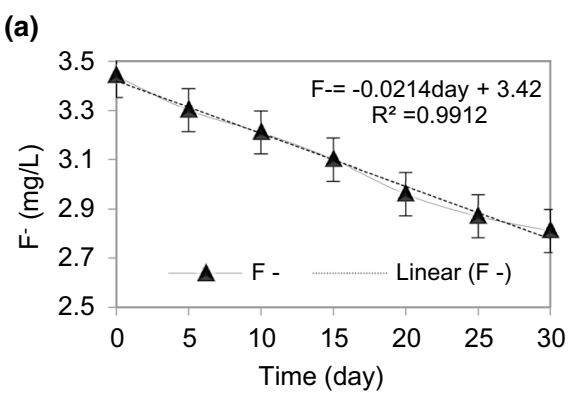

(b)

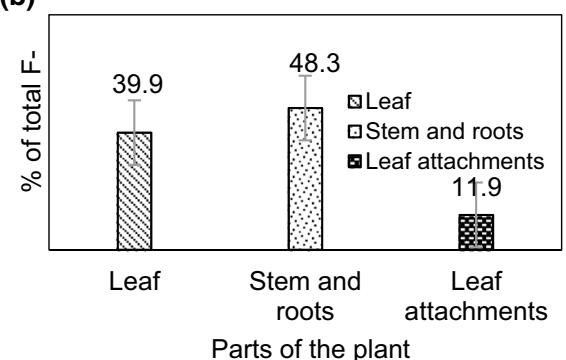

(c)

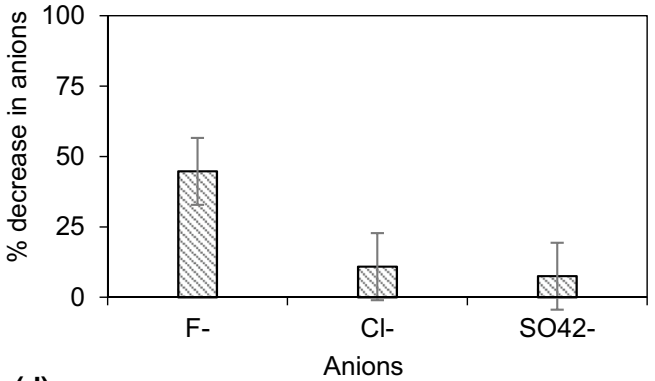

(d)

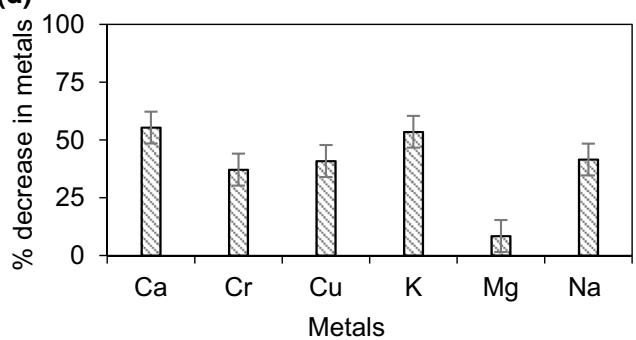

(a) 1

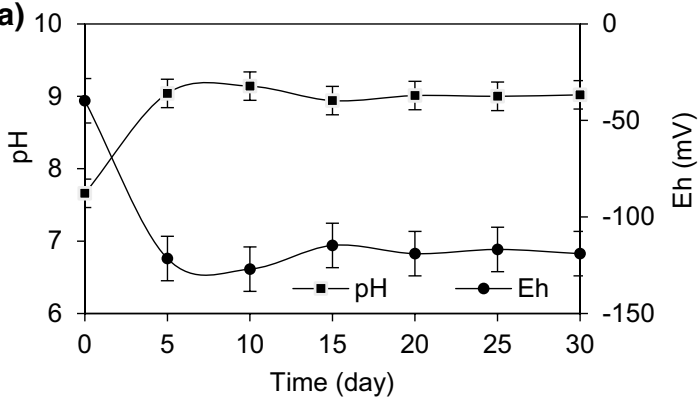

(b)

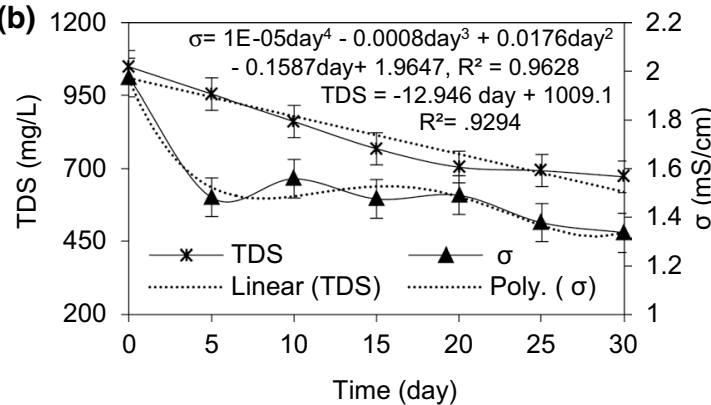

(c)

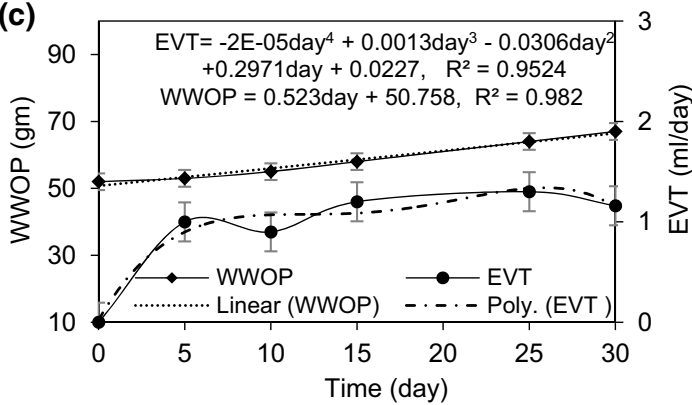

(d)

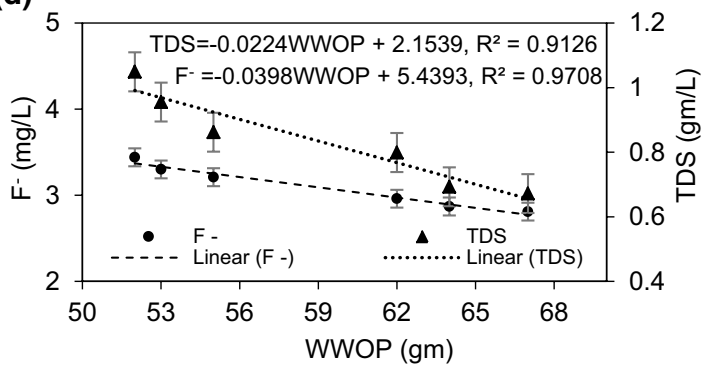

the uniform temperature was maintained in laboratory. d Inverse linear relationships of WWOP with variations in concentrations of $\mathrm{F}^{-}$and TDS

sample mean is likely to be from the population (data) mean. The SE (0.371) indicates that the sample mean is within $\pm 0.742(=2 \times \mathrm{SE})$ of the population mean. Therefore, it indicates that the quality of the measured data is excellent. It has been found that TDS was used by money plant as the nutrients for its growth, which has been indirectly well supported by the decrease in TDS from 1049 to $672 \mathrm{mg} / \mathrm{L}$ and reduction in conductivity from 1.974 to
A linear fit with $R^{2}=0.9294$ showed a linear relation between fluoride concentrations and time, and estimated $\mathrm{SE}=0.564$ has been represented by error bars (Fig. 3b). A polynomial of degree $4\left(\sigma=1 \mathrm{E}-05\right.$ day $^{4}-0.0008$ day $^{3}+0$. 0176 day $^{2}-0.1587$ day +1.9647$)$ has been fitted between conductivity and time. A high value of $R^{2}(0.9628)$ and low SE (0.371) show the excellent fit and good quality of data (Fig. 2b). The SE is defined as an estimate of how far the

\section{SN Applied Sciences}


$1.336 \mathrm{mS} / \mathrm{cm}$ (Fig. 3b). The decrease in fluoride concentration, conductivity and TDS shows that money plant is beneficial for the treatment of both fluoride and TDS. Thus, the money plant is very useful in improving water quality without any additional cost except the disposal cost of the used plants. Money plant can be propagated by branch cutting, stem cutting and tip cutting, which requires very little care.

An excellent linear relationship was obtained by fitting a line between WWOP and time (WWOP $=0.523$ day +50.758 , $R^{2}=0.982$ ), and it has been shown in Fig. 3c. Estimated SE (0.374) is very low, and it signifies the good quality of data. The plot of WWOP against time shows a steady increase in WWOP, and it signifies an increase in biomass (Fig. 3c). The evapotranspiration rate (EVT) per day is calculated by dividing the total water loss $(\mathrm{ml})$ between two consecutive measurements by time interval (day). A polynomial of degree 4 has been fitted with observed EVT and time $\left(E V T=-2 E-05\right.$ day $^{4}+0.0013$ day $^{3}-0.0306$ day $^{2}+0.2971$ day $\left.+0.0227, R^{2}=0.9524\right)$, and SE has been estimated as low as 0.370 (Fig. 3c). EVT initially increases rapidly due to poor control of room temperature and sudden change in climatic temperature. EVT was stabilized after the tenth day of the experiment (Fig. 3c).

The growth of the plant has been observed visually, and photographs were taken every 10 days. The presence of new leaves and branch supports the growth of $E$. aureum in the presence of high TDS. WWOP is measured at regular intervals by using Eq. 1. To understand the relationship between growth in biomass, TDS and $\mathrm{F}^{-}$, a linear fit between WWOP and decrease in $\mathrm{F}^{-}$concentration $\left(F^{-}=-0.0398 W W O P+5.4393, R^{2}=0.9708\right)$ and linear fit between WWOP and TDS (TDS $=-0.0224 W W O P+2.1539$, $R^{2}=0.9126$ ) have been obtained (Fig. $3 \mathrm{~d}$ ). Standard errors in TDS (0.39) and fluoride (0.40) are shown by error bars in Fig. $3 \mathrm{~d}$. It is found that both TDS and $\mathrm{F}^{-}$concentration in water have an inverse linear relationship with WWOP. WWOP is measured at regular intervals by using Eq. 1. WWOP increases with a decrease in concentrations of TDS and fluoride in the water samples that indicates that plant may be utilizing dissolved minerals and solids as the nutrients (Fig. 3d). Reduction in concentrations of anions and metals confirms the capability of the money plant as a TDS accumulator, which is well supported by TDS measurements (Fig. 3b). Additionally, it has been observed that there were no dead biomass and precipitates. Therefore, there was no possibility of occurrence of chemical precipitation of fluoride.

Disposal of plants after phytoremediation may be performed through composting, pyrolysis, gasification, or combustion of plants [38]. However, phytomining, a process of extraction of accumulated fluoride from the used plant, could be helpful in safe disposal of the plants and reusing the extracted fluoride [39]. An appropriate scheme for disposal of used plants needs to be considered before implementing remediation of fluorided water and estimating the cost-effectiveness of the proposed method.

\section{Summary and conclusions}

Preliminary results demonstrate the money plant could be a cost-effective and sustainable tool for defluoridation of water. In this study, unlike phytoremediation studies reported in the literature, no chemicals or costly growth media were used for growing plants. Results obtained from water physicochemical analysis confirm that money plant can be used as an accumulator of trace metals and other anionic contaminants such as chloride and sulfate. More than $50 \%$ of fluoride is accumulated in leaf and leaf attachments of the plant. Thus, disposal of leaf and leaf attachments needs utmost care to avoid induction of fluoride in any natural or engineered systems. This study indicates that defluoridation of water using a money plant is almost free of cost except for the cost of disposal of used plants and eco-friendly. The proposed technique is straightforward to use, and it does not need any specific technical knowledge. It has been recommended that phytoremediation of fluoride using money plant might be useful in defluoridation of water and removal of trace metals. Furthermore, depleted concentrations of $\mathrm{Cr}(37.18 \%)$ and $\mathrm{Cu}(40.88 \%)$ in water samples indicate the possibility phytoextraction of dissolved heavy metals by the E. aureum, and it needs to be investigated in future studies. Nevertheless, this experimental study can be a breakthrough in phytoremediation research for defluoridation of water.

Acknowledgements Authors are sincerely thankful to the Director, CSIR-NGRI, Hyderabad, for his permission to publish this work and providing financial support to conduct laboratory studies. We greatly acknowledge the Principal and the Head Mistress of Delhi Public School, Nacharam, Hyderabad (India), for allowing their students to conduct the project at the Biogeophysics Laboratory in CSIR-NGRI, Hyderabad, India. We are also thankful to the anonymous reviewers for improving the manuscript through their constructive comments and suggestions.

\section{Compliance with ethical standards}

Conflict of interest The authors declare no conflict of interest.

\section{References}

1. Tomar V, Kumar D (2013) A critical study on efficiency of different materials for fluoride removal from aqueous media. Chem Cent J 7(1):51-65. https://doi.org/10.1186/1752-153x-7-51

2. Chouhan S, Flora SJS (2010) Arsenic and fluoride: two major ground water pollutants. Indian J Exp Biol 48(07):666-678 
3. Meenakshi, Garg VK, Kavita, Renuka, Malik A (2004) Groundwater quality in some villages of Haryana, India: focus on fluoride and fluorosis. J Hazard Mater 106(1):85-97. https://doi. org/10.1016/j.jhazmat.2003.09.007

4. Bailey K, Chilton J, Dahi E (2006) Fluoride in drinkingwater. Who series in drinking water quality. World Health Organization. http://worldcat.org. https://www.myilibrary. com?id=84162

5. Rao NS (1997) The occurrence and behaviour of fluoride in the groundwater of the Lower Vamsadhara River basin, India. Hydrol Sci J 42(6):877-892. https://doi.org/10.1080/026266697094920 85

6. Carrillo-Rivera JJ, Cardona A, Edmunds WM (2002) Use of abstraction regime and knowledge of hydrogeological conditions to control high-fluoride concentration in abstracted groundwater: San Luis Potosí basin, Mexico. J Hydrol 261(14):24-47. https://doi.org/10.1016/S0022-1694(01)00566-2

7. Yadav AK, Kaushik CP, Haritash AK, Kansal A, Rani N (2006) Defluoridation of groundwater using brick powder as an adsorbent. J Hazard Mater 128(2-3):289-293. https://doi. org/10.1016/j.jhazmat.2005.08.006

8. Chidambaram S, Manikandan S, Ramanathan AL, Prasanna MV, Thivya C, Karmegam U, Thilagavathi R, Rajkumar K (2013) A study on the defluoridation in water by using natural soil. Appl Water Sci 3(4):741-751. https://doi.org/10.1007/s1320 1-013-0122-1

9. Sivasankar V, Ramachandramoorthy T, Chandramohan A (2010) Fluoride removal from water using activated and $\mathrm{MnO}_{2}$-coated tamarind fruit (Tamarindus indica) shell: batch and column studies. J Hazard Mater 177(1-3):719-729. https://doi.org/10.1016/j. jhazmat.2009.12.091

10. Gao S, Cui J, Wei Z (2009) Study on the fluoride adsorption of various apatite materials in aqueous solution. J Fluor Chem 130(11):1035-1041. https://doi.org/10.1016/j.jfluc hem.2009.09.004

11. Kemer B, Ozdes D, Gundogdu A, Bulut VN, Duran C, Soylak M (2009) Removal of fluoride ions from aqueous solution by waste mud. J Hazard Mater 168(2-3):888-894. https://doi. org/10.1016/j.jhazmat.2009.02.109

12. Singh KP, Agrawal K (2015a) Biogeophysical signals associated with bioremediation of fluoride contamination. In: 52nd annual convention of Indian Geophysical Union on'near surface earth system sciences', National Centre for Antarctic and Ocean Research, Goa, 2015. Solid Earth Geosciences. Indian Geophysical Union, pp 98-99

13. Singh KP, Agrawal K (2015b) Biostimulated treatment of fluoride contamination in aquatic systems. In: 52 nd annual convention of Indian Geophysical Union on 'Near surface earth system sciences', National Centre for Antarctic and Ocean Research, Goa, 2015. Indian Geophysical Union, Hyderabad, p 96

14. Lee HH, Chen G, Yue PL (2001) Integration of chemical and biological treatments for textile industry wastewater: a possible zero-discharge system. Water Sci Technol 44(5):75-83

15. Brindha K, Rajesh R, Murugan R, Elango L (2011) Fluoride contamination in groundwater in parts of Nalgonda District, Andhra Pradesh, India. Environ Monit Assess 172(1):481-492. https:// doi.org/10.1007/s10661-010-1348-0

16. Rao NVR, Rao N, Surya Prakash Rao K, Schuiling RD (1993) Fluorine distribution in waters of Nalgonda District, Andhra Pradesh, India. Environ Geol 21(1):84-89. https://doi.org/10.1007/bf007 75055

17. Jain SK, Vasudevan P, Jha NK (1989) Removal of some heavy metals from polluted water by aquatic plants: studies on duckweed and water velvet. BIOWAS Biol Wastes 28(2):115-126

18. Rezania S, Ponraj M, Talaiekhozani A, Mohamad SE, Md Din MF, Taib SM, Sabbagh F, Sairan FM (2015) Perspectives of phytoremediation using water hyacinth for removal of heavy metals, organic and inorganic pollutants in wastewater. J Environ Manag 163:125-133

19. Salt DE, Smith RD, Raskin I (1998) Phytoremediation. Annu Rev Plant Physiol Plant Mol Biol 49(1):643-668. https://doi. org/10.1146/annurev.arplant.49.1.643

20. Joy CM, Balakrishnan KP (1990) Effect of fluoride on axenic cultures of diatoms. Water Air Soil Pollut 49(3):241-249. https://doi. org/10.1007/bf00507067

21. Shirke PA, Chandra P (1991) Fluoride uptake by duckweed Spirodela polyrrhiza. Flouride-Quaterley reports 24(3):109-112

22. Zhou J, Gao J, Liu Y, Ba K, Chen S, Zhang R (2012) Removal of fluoride from water by five submerged plants. Bull Environ Contam Toxicol 89(2):395-399. https://doi.org/10.1007/s0012 8-012-0710-z

23. Sinha $S$, Saxena $R$, Singh $S$ (2000) Fluoride removal from water by Hydrilla verticillata (I.f.) Royle and its toxic effects. Bull Environ Contam Toxicol 65(5):683-690. https://doi.org/10.1007/s0012 800177

24. Zhang L, Li Q, Ma L, Ruan J (2013) Characterization of fluoride uptake by roots of tea plants (Camellia sinensis (L.) O. Kuntze). Plant Soil 366(1):659-669. https://doi.org/10.1007/s1110 4-012-1466-2

25. Singh G, Kumari B, Sinam G, Kriti Kumar N, Mallick S (2018) Fluoride distribution and contamination in the water, soil and plants continuum and its remedial technologies, an Indian perspective-a review. Environ Pollut (Barking, Essex: 1987) 239:95-108. https://doi.org/10.1016/j.envpol.2018.04.002

26. Karmakar S, Mukherjee J, Mukherjee S (2016) Removal of fluoride contamination in water by three aquatic plants. Int J Phytorem 18(3):222-227. https://doi.org/10.1080/15226 514.2015.1073676

27. Banerjee A, Roychoudhury A (2019) Fluorine: a biohazardous agent for plants and phytoremediation strategies for its removal from the environment. Biol Plant 63(1):104-112. https://doi. org/10.32615/bp.2019.013

28. Koblar A, Tavcar G, Ponikvar-Svet M (2015) Stress syndrome response of nettle (Urtica dioica L.) grown in fluoride contaminated substrate to fluoride and fluorine accumulation pattern. J Fluor Chem 172:7-12

29. Griffiths M, Huxley A, Levy M (1999) The new RHS dictionary of gardening. In: Huxley A, Griffiths M, Levy M (eds) Dictionary of gardening. Macmillan, London

30. Kamel HA, Eskander SB, Aly MAS (2007) Physiological response of Epipremnum aureum for cobalt-60 and cesium-137 translocation and rhizofiltration. Int J Phytorem 9(5):403-417. https://doi. org/10.1080/15226510701606281

31. Srivastava N, Shwarupa S, Bhagyawant S (2011) Comparative study on the anti-termite, antimicrobial and antioxidant activity of leaf and root extracts of Pothos aurea (Epipremnum aureum L.). J Pharm Res Clin Pract 1:1-11

32. Greenberg AE, Clesceri LS, Eaton AD (1992) Standard methods: for the examination of water and wastewater. American Public Health Association, Washington

33. Hoagland DR, Arnon DI (1938) The water-culture method for growing plants without soil, vol C347. College of Agriculture, Agricultural Experiment Station, University of California, Berkeley

34. Skoog DA, Leary JJ (1992) Principles of instrumental analysis, 4th edn. In. Saunders, New York

35. Harris DC (1991) Quantitative chemical analysis Solutions manual, 3rd edn. W.H. Freeman, New York

36. Villa AE (1979) Rapid method for determining fluoride in vegetation using an ion-selective electrode. Analyst 104(1239):545-551 
37. Singh KP, Doherty R, Ntarlagiannis D, Elliot T (2007) Electrical potentials associated with microbial activity in a Winogradsky Column. Eos Trans AGU 88

38. Sas-Nowosielska A, Kucharski R, Małkowski E, Pogrzeba M, Kuperberg JM, Kryński K (2004) Phytoextraction crop disposalan unsolved problem. Environ Pollut 128(3):373-379. https:// doi.org/10.1016/j.envpol.2003.09.012
39. Brooks RR, Chambers MF, Nicks LJ, Robinson BH (1998) Phytomining. Trends Plant Sci 3(9):359-362. https://doi. org/10.1016/S1360-1385(98)01283-7

Publisher's Note Springer Nature remains neutral with regard to jurisdictional claims in published maps and institutional affiliations. 